\title{
Unwrapped hydroxyapatite orbital implants: our experience in 347 cases
}

\author{
Manvi M. Sobti ${ }^{1} \cdot$ Fatemeh Shams $^{1} \cdot$ Lona Jawaheer $^{1} \cdot$ Paul Cauchi $^{1} \cdot$ Vikas Chadha $^{1}$
}

Received: 1 March 2019 / Revised: 14 April 2019 / Accepted: 13 August 2019 / Published online: 16 September 2019

(c) The Author(s), under exclusive licence to The Royal College of Ophthalmologists 2019

\begin{abstract}
Objectives To report the results of a large case series of enucleations with primary insertion of an unwrapped hydroxyapatite (HA) orbital implant.

Methods We retrospectively reviewed consecutive enucleations with primary orbital (HA) implant insertion performed at the Scottish Ocular Oncology Service, Glasgow between 1990 and 2014. The unwrapped hydroxyapatite orbital implant was placed in the posterior portion of the socket and recti muscles sutured end-to-end over the implant.

Results Out of 347 consecutive enucleations, the indication for enucleation was tumour-related pathology in $59.7 \%$ and painful blind eye in $40.3 \%$. Majority (70\%) received an implant of 22-mm diameter. At an average follow-up of 3.5 years, complications included post-enucleation socket syndrome (11.5\%), chronic discharge (9.2\%), chronic pain (4.3\%), recurrent conjunctival infection $(2.3 \%)$,conjunctival cysts $(2 \%)$, contracted socket $(1.4 \%)$, implant exposure (1.2\%), haematoma $(0.6 \%)$ and ill-fitting prosthesis $(0.6 \%)$. Implant exposure $(1.2 \%, n=4)$ occurred at a mean of 4.5 months post surgery and was managed by temporalis fascia graft $(n=1)$, tarsoconjunctival flap $(n=1)$, implant removal $(n=1)$ and observation $(n=1)$. Overall, $9.8 \%$ of patients needed further surgery including lower lid tightening (4.3\%), ptosis repair $(2.3 \%)$, conjunctival cyst excision (1.2\%), fornix reconstruction (1.2\%), graft/flap for exposure $(0.6 \%)$ and implant removal $(0.3 \%)$. Conclusions A low rate of implant exposure indicates that absence of wrapping material around hydroxyapatite orbital implants does not compromise surgical outcomes and has the added benefit of reduced surgical time and avoidance of complications from wrapping materials. Posterior implant placement and end-to-end recti suturing contribute to the success of the procedure.
\end{abstract}

\section{Introduction}

Enucleation may be indicated in the treatment of intraocular tumours, unsalvageable eyes following trauma, painful blind eyes and phthisical eyes [1,2]. The aims of managing an anophthalmic socket are to achieve adequate volume replacement, good mucosal lining and deep fornices that

Meeting presentation: This material has been presented as an oral presentation at the British 27 Oculoplastic Surgery Society Meeting, London in 2017. Part of this study was presented at the Oxford 28 Ophthalmological Congress, Oxford in 2009 and the ESOPRS Meeting, Budapest in 2014.

Manvi M. Sobti

manvimanu.sobti@nhs.net

1 Tennent Institute of Ophthalmology, Gartnavel General Hospital, 1053 Great Western Road, Glasgow G12 0YN, United Kingdom retain a prosthetic shell. The socket should be comfortable, free of discharge and impart good prosthesis motility with a life-like appearance.

Hydroxyapatite (HA) orbital implants have been widely used since 1989 [3]. They have a porous structure resembling the haversian system of normal lamellar bone that provides a passive latticework for fibrovascular ingrowth into the implant. The implant gets bio-integrated with the orbital tissues and this resists extrusion and migration $[4,5]$. Complete vascularisation deep into the implant core helps prevent infection [6]. The relatively light weight of the implant avoids pressure over the lower lids, decreasing the risk of lower eyelid sag and upper lid sulcus deformity [7].

The HA implant can be complicated by implant exposure. The incidence of implant exposure varies from 0 to $25.8 \%$ [7]. Management of the exposure frequently needs further surgical intervention. Implant infections can be difficult to treat and may require removal of the entire 

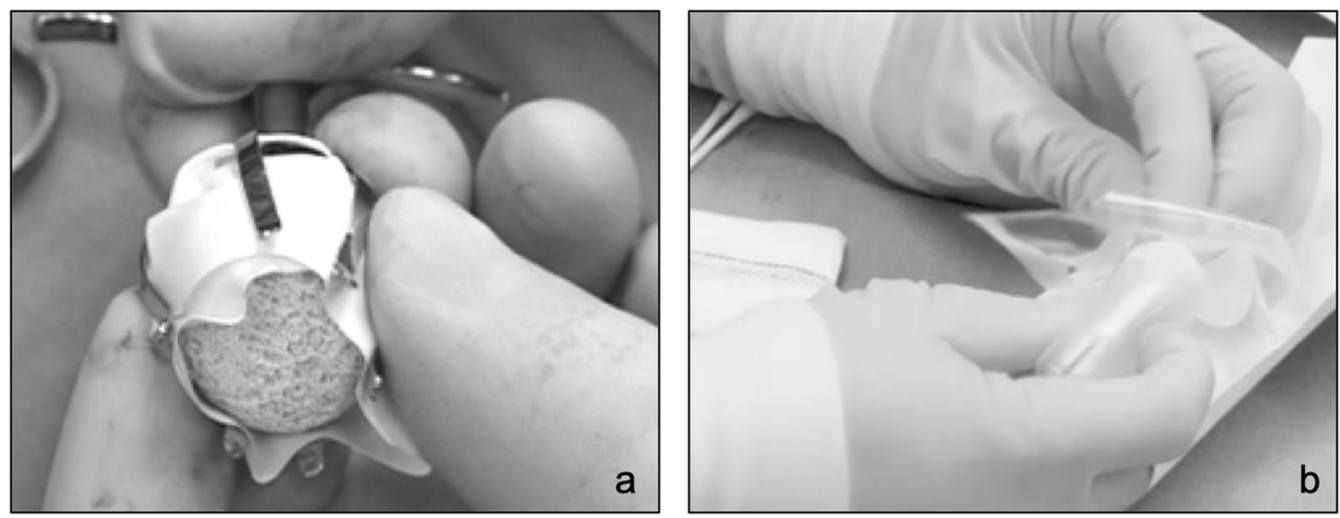

Fig. 1 a Hydroxyapatite implant was wrapped in sterile paper when used with a metal injector. b Hydroxyapatite implant used with a plastic sleeve

implant. Also, the rough surface of the implant makes it a challenge to insert.

Wrapping orbital implants can facilitate their insertion into the socket and improve motility by allowing precise extraocular muscle attachment [3, 8, 9]. Some authors believe that the rough surface of the porous implant abrades the overlying tissues resulting in exposure and thus advocate wrapping [10-12]. However, several authors have reported that wrapping increases exposure rates by acting as a barrier to bio-integration [6, 7, 9, 13-15]. A 2004 survey of the American Society of Ophthalmic Plastic and Reconstructive Surgery members showed that most implants $(60 \%)$ were unwrapped, and the use of wrapping material was declining [16]. In contrast, Vishwanath et al. [17] in their survey of ophthalmologists in the UK in 2007 found that $57 \%$ used wrapped implants. Thus, there is still a debate about the benefits of wrapping orbital implants.

Unwrapped HA orbital implants have been used at the Scottish Ocular Oncology Service, Glasgow since 1990 due to their excellent bio-integration properties. Our surgical technique includes the insertion of an unwrapped HA implant deep into the posterior portion of the socket and suturing the recti end-to-end over the implant. We evaluated consecutive enucleations performed over a 24 -year period to evaluate the complication rate.

\section{Methods}

A retrospective review of consecutive enucleations with primary insertion of an unwrapped HA orbital implant was performed. The enucleations were carried out at the Scottish Ocular Oncology Centre, Glasgow between 1990 and 2014. Patients with evisceration, enucleation without implant placement, secondary implant placement, age $<16$ years and incomplete data were excluded.
The surgical technique involved $360^{\circ}$ conjunctival peritomy and dissection in the sub-tenon's plane in all four quadrants. The recti muscles were secured on $6 / O$ polyglactin sutures and disinserted, while the oblique muscles were cauterised and cut. The apical structures were clamped and cut and the eye was removed. Implant size was chosen based on the largest metal sizer that could comfortably fit into the socket. The HA implant was then inserted into the posterior portion of the socket ensuring that the recti and conjunctiva were reflected externally. No wrapping material was used. The insertion was performed either with a metallic injector or a plastic sleeve depending on surgeon preference (Fig. 1). With the metallic injector, a sterile slippery paper was used to cover the implant during insertion. With the plastic sleeve, no additional interface was needed. Once the implant was in the posterior-most portion of the orbit, the sterile slippery paper/plastic sleeve was removed while maintaining continuous downward pressure on the implant. If the implant demonstrated any tendency to surface up, it was removed and the procedure repeated. The recti were sutured end-to-end to form a central cruciate knuckle over the implant surface. The tenons capsule and conjunctiva were closed in separate layers. A large conformer was then placed in the conjunctival sac. No pegging was carried out. The conformer was replaced by a custom-made prosthetic shell 8 weeks postoperatively.

Data collection included patient demographics, indication for enucleation, details of previous ocular surgery, implant size, socket status at follow-up, complications and any secondary procedures required. Forty-two consecutive patients were surveyed by phone between 3 and 18 months after their surgery to assess their satisfaction with the motility of the prosthesis.

The ethics committee ruled that approval was not required for this study. The Tenets of the Declaration of Helsinki were followed while performing the study. 
Table 1 Indications for enucleation

\begin{tabular}{llc}
\hline Indication for enucleation & $n$ & Percentage \\
\hline Tumour related & $\mathbf{2 0 7}$ & $59.70 \%$ \\
Intraocular tumours & & \\
$\quad$ Uveal Melanoma & 194 & $55.90 \%$ \\
$\quad$ Other intraocular tumours ${ }^{\mathrm{a}}$ & 8 & $2.30 \%$ \\
Extraocular tumours & 5 & $1.40 \%$ \\
Non-tumour painful blind eye/phthisis & $\mathbf{1 4 0}$ & $40.30 \%$ \\
Trauma & 56 & $16.10 \%$ \\
Anterior segment pathology & 23 & $6.60 \%$ \\
Vitreo-retinal pathology & 17 & $4.90 \%$ \\
Glaucoma & 17 & $4.90 \%$ \\
Congenital & 9 & $2.60 \%$ \\
Miscellaneous & 10 & $2.90 \%$ \\
Infections/inflammations & 8 & $2.30 \%$ \\
\hline
\end{tabular}

$n=1$ phthisical eye following attempted removal of optic nerve glioma, $n=1$ ocular lymphoma (diffuse large B cell) with a painful blind eye, $n=1$ optic nerve glioma, $n=1$ retinal astrocytoma with rubeotic glaucoma and a phthisical painful eye, $n=1$ ocular metastasis from breast cancer, $n=1$ ocular metastasis from thyroid cancer, $n=1$ ocular metastasis

${ }^{\mathrm{a}} n=1$ retinal vasoproliferative tumour

\section{Results}

Our cohort included 347 patients with 190 males and 157 females with an average age of 57 years (16-92 years). There were 170 right and 177 left eyes. The average followup was 3.5 years ( 1 month to 18 years).

The enucleations were performed for tumour-related indications in $59.7 \%$ and non-tumour-related painful, blind or phthisical eyes in $40.3 \%$ of the patients. (Details in Table 1).

Out of the 194 patients who had an enucleation for uveal melanoma, 60.8\% $(n=118)$ had previous surgery (ruthenium plaque brachytherapy and/or tantalum marker insertion followed by proton beam radiation). Size 22 implant was used in $70 \%$ of patients, size $20 \mathrm{~mm}$ in $24.6 \%$, size 18 in $4.5 \%$ and size 16 in $0.8 \%$. Complications included postenucleation socket syndrome $(11.5 \% n=40)$, chronic discharge $(9.2 \% n=32)$, chronic pain $(4.3 \% n=15)$, recurrent conjunctival infection (2.3\% $n=8)$, conjunctival cysts/ granuloma/allergic reaction $(2 \% n=7)$, contracted socket $(1.4 \% n=5)$, implant exposure $(1.2 \% n=4)$, haematoma $(0.6 \% n=2)$ and ill-fitting prosthesis $(0.6 \% n=2)$. Implant exposures $(n=4)$ occurred $2-7$ months (mean 4.5 months) post surgery. Table 2 lists the details of the patients who developed exposure of the orbital implant. Overall, $9.8 \%$ of the patients needed further surgery including lower lid tightening in $4.3 \%(n=15)$, ptosis repair in $2.3 \%(n=8)$, conjunctival cyst removal in $1.2 \%(n=4)$, fornix reconstruction in $1.2 \%(n=4)$, grafts/flaps for exposure repair in $0.6 \%(n=2)$ and implant removal in $0.3 \%(n=1)$.

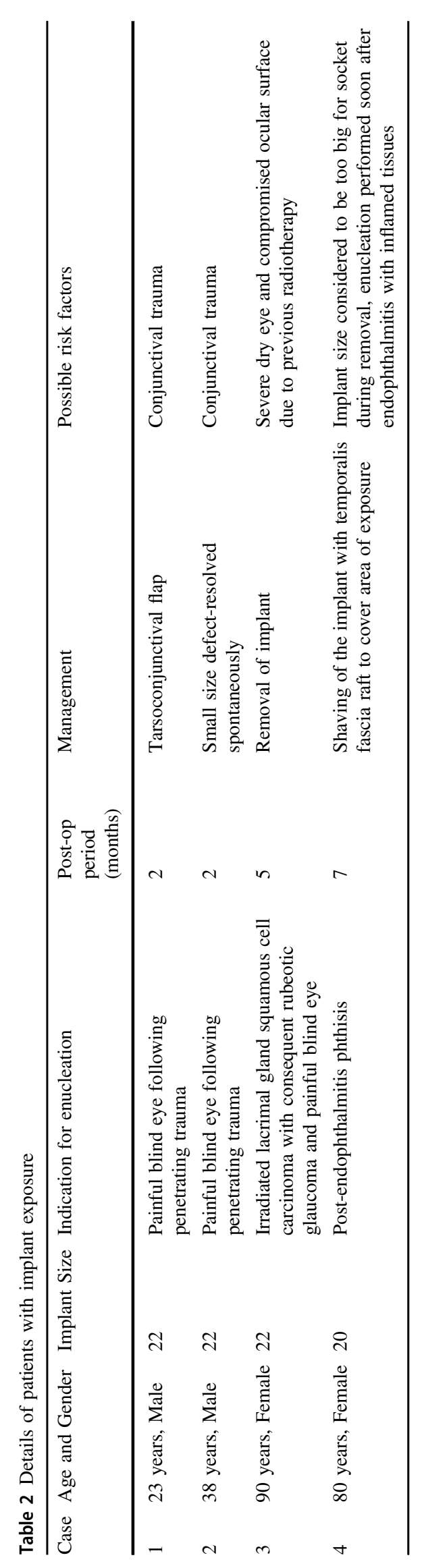


The patient satisfaction survey conducted on 42 consecutive patients revealed that 27 patients $(64.3 \%)$ judged their artificial eye motility to be good and $10(23.8 \%)$ judged it to be fair.

\section{Discussion}

Over a mean follow-up period of 3.5 years, our cohort had a low implant exposure rate and no cases of implant migration or extrusion. To the best of our knowledge, this is the largest series of unwrapped HA orbital implant insertions following enucleation in adults.

Majority of the enucleations in our cohort were tumourrelated as these cases were performed at an oncology service. Enucleations performed for intraocular malignancies tend to have lower implant exposure rate due to relatively healthy conjunctiva and tenons fascia [14, 18]. However, prior surgery is a known risk factor for implant exposure [7, 19, 20]. Of all our enucleations for intraocular malignancies, $60 \%$ had previous ocular surgery including ruthenium plaque brachytherapy or placement of tantalum markers followed by proton beam therapy. Even in this subgroup, the complication rate was low, with no cases of implant exposure; suggesting that the risk of exposure in can be minified by altering the surgical technique.

Comparison with retrospective studies is difficult due to the heterogeneity in age groups, indications for enucleation, implant materials, surgical techniques and follow-up periods. The exposure rate $(1.2 \%)$ in our cohort compares favourably with that reported in literature (0-25.8\% for HA implants) [7]. Among the several published series, Yoon et al. [21] report the largest series $(n=805)$ of wrapped HA implants with an exposure rate $4.5 \%$. Ye et al. [7] report a large series of unwrapped HA implants $(n=234)$ with an exposure rate of $4.7 \%$. Table $3[5,9,22-29]$ and Table 4 [7, 13, 14, 18] list the major retrospective studies with implant exposure rates.

The implant exposures occurred early in the postoperative period, indicating that it was a result of compromised conjunctiva and tenons facia rather than incomplete implant vascularisation. The risk factors identified were traumatised ocular surface, severe dry eye post-radiation and inflamed ocular surface following endophthalmitis. The techniques used to manage exposure have been previously described [30, 31].

Implant exposure is believed to be related to delayed fibrovascular ingrowth into the implant [7, 21]. Histopathological studies in animal models showed significantly greater rate of fibrovascularization in bare HA spheres compared with scleral wrapped implants. Further, placement of access holes in the scleral wrapping greatly improved the fibrovascularization rate [15]. Shields et al. reported histological evidence of rapid vascularisation of the HA implant within weeks of implantation, and this vascular ingrowth was mainly concentrated in the areas of scleral windows [32]. Creating large scleral windows to facilitate vascularisation is a well-accepted technique. Eliminating the wrapping material thus removes any potential barrier to fibrovascularization [6].

The advantages of introducing an unwrapped implant include the immediate adherence of the orbital tissues to the rough surface of the implant. This reduces tension on the sutures [14] and prevents early exposure. The entire surface area of the implant is bare and available for bio-integration.

Wrapping materials add to the cost, complexity and duration of the operation [6]. Sclera and vicryl mesh are popular wrapping materials. Sclera has theoretical risks of transmission of infectious agents and rejection [6]. Late implant exposure can occur after spontaneous absorption of the sclera in presence of an incompletely organised implant $[14,20]$. Vicryl mesh has a rough implant-tissue interface leading to difficulties in implantation and subsequent erosion of overlying tissue [33].

To facilitate bio-integration and protect the conjunctival erosion, some surgeons cover only the anterior surface of the implant with a scleral cap. Toh et al. studied exposure rates in 150 enucleations with bone derived HA implants and compared unwrapped implants to those with an anterior scleral cap [14]. The exposure was significantly higher in the scleral wrapped versus the unwrapped group. Several other retrospective studies support unwrapped porous implants [6, 7, 9, 13].

We believe that posterior placement of the implant is crucial in reducing the exposure rate. The surgical technique used in our cohort ensures deep orbital implantation by keeping the implant covered during the process of insertion and allowing contact with the orbital tissues only when the implant is in the posterior-most portion of socket. The implant is either covered in a sterile paper during insertion with a metal injector or inserted with a smooth polythene glide. Downward pressure is applied on the implant till no further excursion is possible. Posterior placement is confirmed when the surgeon does not experience a spring or bounce-back, i.e. there is only minimal soft tissue between the implant and the orbital bones. The sterile paper or glide is then withdrawn while maintaining continuous downward pressure on the implant. Once the bare implant is in the socket, the tenons fascia and muscles adhere to the rough surface of the implant. This keeps the implant in place, resisting upward recoil. Keeping the implant covered during insertion thus prevents the occurrence of "cactus syndrome", a phenomenon that occurs when an orbital implant is forced into the tissues during implantation and the implant surface drags the superficial tissues into the depths 
Table 3 Retrospective series of enucleations with orbital implant placement in adults

\begin{tabular}{|c|c|c|c|c|}
\hline Study, year & Number & Procedure & $\begin{array}{l}\text { Implant type, wrapping and } \\
\text { muscle closure technique }\end{array}$ & Exposure rate \\
\hline Shields 1994 & 250 & En & $\begin{array}{l}\text { HA } \\
\text { Wrapped }\end{array}$ & $1.60 \%$ \\
\hline Oestreicher 1997 & 100 & En, Ev, S & $\begin{array}{l}\text { HA } \\
\text { Wrapped in Dexon mesh } \\
\text { or sclera } \\
\text { Muscles to implant }\end{array}$ & $3 \%$ \\
\hline Christmas (26) 1998 & 342 & En & $\begin{array}{l}\text { Acrylic, silicon, glass, HA, PP } \\
\text { Wrapped in scleral in } 84 \%\end{array}$ & $1.20 \%$ \\
\hline Inkster (27) 2002 & 110 & En, $S$ & $\begin{array}{l}\text { HA } \\
\text { Wrapped in sclera plus } \\
\text { covered with scleral patch } \\
\text { Muscles sutured to scleral } \\
\text { windows }\end{array}$ & $0 \%$ \\
\hline Jordon (28) 2004 & 158 & En, Ev, S & $\begin{array}{l}\text { HA } \\
\text { Mixed: wrapped (142) and } \\
\text { unwrapped (8) }\end{array}$ & $\begin{array}{l}7.6 \% \text { unpegged } \\
\text { implants } \\
3.7 \% \text { after pegging }\end{array}$ \\
\hline Perry (29) 2002 & 27 & En & $\begin{array}{l}\text { Bone derived HA } \\
\text { Unwrapped } \\
\text { Muscles sutured end to end }\end{array}$ & $7 \%$ \\
\hline Perry (12) 2004 & 26 & En & $\begin{array}{l}\text { HA, PMMA, PP } \\
\text { Unwrapped } \\
\text { Muscles sutured end to end } \\
\text { Posterior implant placement }\end{array}$ & $0 \%$ \\
\hline Liang (30) 2006 & 211 & $\begin{array}{l}\text { En, Ev } \\
\text { (Trauma) }\end{array}$ & $\begin{array}{l}\text { HA } \\
\text { Mixed: } 77 \text { cases wrapped in } \\
\text { sclera with windows, } 66 \text { cases } \\
\text { unwrapped }\end{array}$ & $\begin{array}{l}1.3 \% \text { in wrapped } \\
\text { implants } \\
10.6 \% \text { in unwrapped } \\
\text { implants }\end{array}$ \\
\hline Gupta (31) 2007 & 104 & $\begin{array}{l}\text { En (Choroidal } \\
\text { melanoma) }\end{array}$ & $\begin{array}{l}\text { HA } \\
\text { Wrapped in bovine } \\
\text { pericardium (Tutopatch) } \\
\text { Muscles to wrapping material }\end{array}$ & $\begin{array}{l}\text { Wound } \\
\text { dehiscence } 2.9 \%\end{array}$ \\
\hline Shields 2007 & 126 & En & $\begin{array}{l}\text { Polymer coated HA } \\
\text { Unwrapped } \\
\text { Muscles sutured to the implant }\end{array}$ & $2 \%$ \\
\hline Yoon 2008 & 802 & En, Ev, S & $\begin{array}{l}\text { HA } \\
\text { Wrapped (Sclera/dura/vicryl } \\
\text { mesh/polyester-urethane) } \\
\text { Muscles sutured to wrapping } \\
\text { material }\end{array}$ & $\begin{array}{l}2.1 \% \text { before pegging } \\
4.0 \% \text { after pegging }\end{array}$ \\
\hline Ricaud (32) 2014 & 704 & En & $\begin{array}{l}\text { HA } \\
\text { Wrapped in polyglactin mesh } \\
\text { (Included paediatric } \\
\text { age group) }\end{array}$ & $\begin{array}{l}\text { Major } \\
\text { dehiscence } 0.42 \% \\
\text { implant removal } 0.71 \%\end{array}$ \\
\hline Lin 2016 & 256 & En, Ev & $\begin{array}{l}\text { HA, Bioceramic, medpore } \\
\text { Wrapped in vicryl mesh and } \\
\text { scleral cap placed anteriorly } \\
\text { Muscles sutured to wrapping } \\
\text { material }\end{array}$ & $\begin{array}{l}24.7 \% \text { in } \mathrm{HA} \\
23.5 \% \text { in Bio ceramic } \\
76.5 \% \text { in medpore }\end{array}$ \\
\hline Present study & 347 & En & $\begin{array}{l}\text { Unwrapped HA } \\
\text { End-to-end recti suturing }\end{array}$ & $1.20 \%$ \\
\hline
\end{tabular}

En enucleation, $E v$ evisceration, $S$ secondary implant placement, $H A$ hydroxyapatite implant

of the socket [34]. It is believed that the trapped superficial tissues gradually return to their original relaxed position with progressive migration of the ball towards the surface and eventual implant erosion through the conjunctiva.
Several authors have previously advocated deep orbital placement of the implant [9, 20, 22, 35].

End-to-end muscle suturing forms an interface between the rough HA surface and the overlying tenons fascia and thus 


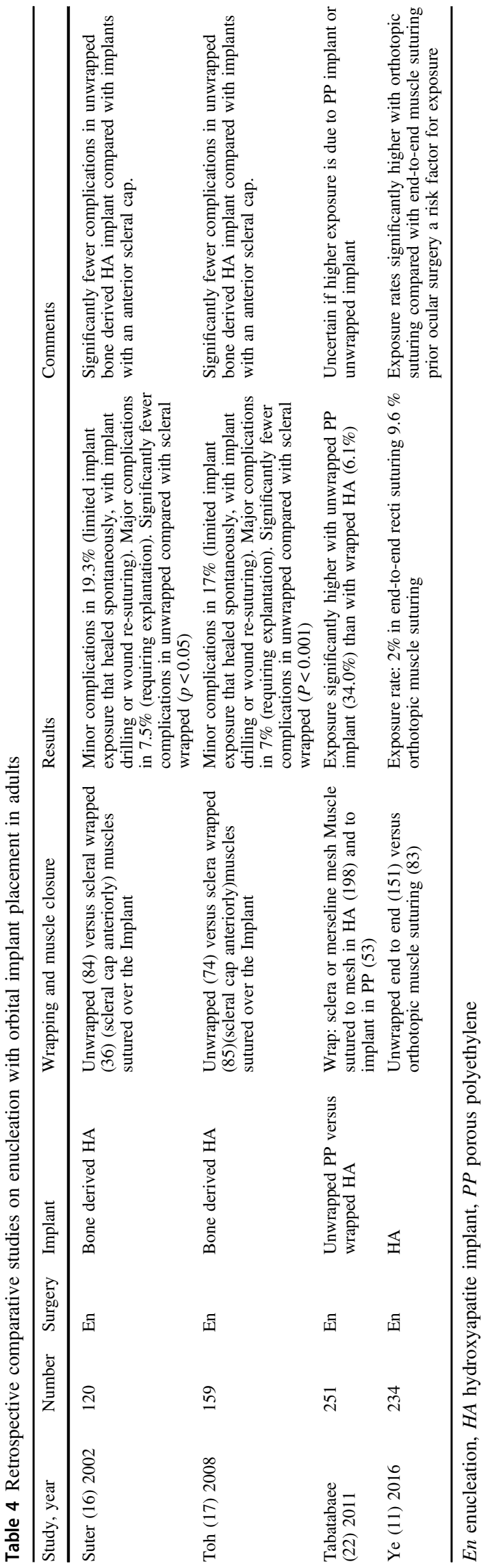

protects the conjunctiva. The highly vascular extraocular muscles lie in close apposition with the bare implant, further encouraging fibrovascular ingrowth. The implant is secured in the intraconal space, and this reduces tension in the conjunctival wound $[7,15]$. Finally, this technique allows for three layers anterior to the implant- extraocular muscles, sub-tenon's tissue and conjunctiva. A retrospective study conducted by $\mathrm{Ye}$ at al. [7] evaluated implant exposure in 234 unwrapped HA implants following enucleation and compared end-to-end recti suturing with orthotopic muscle suturing. The orthotopic muscle suturing group had an eightfold higher risk of implant exposure compared with the end-to-end suturing group.

The limitation of using end-to-end recti suturing is the compromise in prosthesis motility. The muscle is put on a stretch, resulting in "fadinisation" and this reduces range of movement. A prospective randomised study [1] reported significantly better motility with myoconjunctival suturing technique compared with muscle imbrication and to orthotopic muscle suturing to a scleral cap. However, in a randomised masked study by Long et al. [6], a masked observer compared the motility between wrapped and unwrapped implants. They did not find significant difference in motility between the two groups. Perry and Tam [9] also reported acceptable motility in their series of unwrapped implants in which the adjacent recti were sutured to form a sling over the implant. In the small subgroup of our patients who underwent patient satisfaction surveys, the reduced motility was not to be perceived a significant problem. However, the number of patients surveyed was small and a majority of them had intraocular tumours. The relief of the tumour being removed may cloud their subjective responses. Incomplete documentation of artificial eye motility constitutes a limitation of our study.

Concluding from this, we report a large series of enucleations with primary insertion of an unwrapped HA orbital implant with a long follow-up. The implant exposure rate was low. Absence of wrapping material around HA orbital implants did not compromise surgical outcomes. Placement of the bare implant deep in the socket and end-to-end recti suturing enhances bio-integration of the implant and contributes to the low exposure rate. Further studies are required to analyse the compromise of prosthetic motility from this technique.

\section{Summary table}

\section{What was known before?}

- Hydroxyapatite orbital implants may be complicated by implant exposure that is challenging to treat. 


\section{What this study adds?}

- Posterior placement of the unwrapped hydroxyapatite prevents "cactus syndrome" leading to a low implant exposure rate.

- End-to-end recti suturing and absence of wrapping material facilitates bio-integration of the hydroxyapatite implant.

Acknowledgements Susan Ewan for facilitating data collection for the study.

Author Contributions Substantial contributions to the conception or design of the work: VC, the acquisition, analysis or interpretation of data: MS, FS, LJ, PC and VC. Drafting the work or revising it critically for important intellectual content: MS, FS, VC and PC. Final approval of the version published: MS, PC and VC. Agreement to be accountable for all aspects of the work in ensuring that questions related to the accuracy or integrity of any part of the work are appropriately investigated and resolved.

\section{Compliance with ethical standards}

Conflict of interest The authors declare that they have no conflict of interest.

Publisher's note Springer Nature remains neutral with regard to jurisdictional claims in published maps and institutional affiliations.

\section{References}

1. Shome D, Honavar S, Raizada K, Raizada D. Implant and prosthesis movement after enucleation. Ophthalmology. 2010; 117:1638-1644.

2. Migliori M. Enucleation versus evisceration. Curr Opin Ophthalmol. 2002;13:298-302.

3. Dutton J. Coralline hydroxyapatite as an ocular implant. Ophthalmology. 1991;98:370-377.

4. Gradinaru S, Popescu V, Leasu C, et al. Hydroxyapatite ocular implant and non-integrated implants in eviscerated patients. J Med Life. 2015;8:90-93.

5. Shields C, Shields J, De Potter P, Singh A. Problems with the hydroxyapatite orbital implant: experience with 250 consecutive cases. Br J Ophthalmol. 1994;78:702-706.

6. Long J, Tann T, Bearden W, Callahan M. Enucleation: is wrapping the implant necessary for optimal Motility? Ophthalmic Plast Reconstr Surg. 2003;19:194-197.

7. Ye J, Gao Q, He J, Gao T, Ning Q, Xie J. Exposure rate of unwrapped hydroxyapatite orbital implants in enucleation surgery. Br J Ophthalmol. 2015;100:860-865.

8. Trichopoulos N, Augsburger J. Enucleation with unwrapped porous and nonporous orbital implants: a 15-year experience. Ophthalmic Plast Reconstr Surg. 2005;21:331-336.

9. Perry J, Tam R. Safety of unwrapped spherical orbital implants. Ophthalmic Plast Reconstr Surg. 2004;20:281-284.

10. Karesh J, Dresner S. High-density porous polyethylene (Medpor) as a successful anophthalmic socket Implant. Ophthalmology. 1994:101:1688-1696.
11. Rernulla H, Rubin P, Shore J, Sutula F, Toaunsend D, Woog J, et al. Complications of porous spherical orbital implants. Ophthalmology. 1995;102:586-593.

12. Li T, Shen J, Duffy M. Exposure rates of wrapped and unwrapped orbital implants following enucleation. Ophthalmic Plast Reconstr Surg. 2001;17:431-435.

13. Suter A, Molteno A, Bevin T, Fulton J, Herbison P. Long term follow up of bone derived hydroxyapatite orbital implants. Br J Ophthalmol. 2002;86:1287-1292.

14. Toh T, Bevin T, Molteno A. Scleral wrap increases the long-term complication risk of bone-derived hydroxyapatite orbital implants. Clin Exp Ophthalmol. 2008;36:756-761.

15. Gayre G, Lipham W, Dutton J. A comparison of rates of fibrovascular ingrowth in wrapped versus unwrapped hydroxyapatite spheres in a rabbit model. Ophthalmic Plast Reconstr Surg. 2002;18:275-280.

16. Su G, Yen M. Current trends in managing the anophthalmic socket after primary enucleation and evisceration. Ophthalmic Plast Reconstr Surg. 2004;20:274-280.

17. Viswanathan P, Sagoo M, Olver J. UK national survey of enucleation, evisceration and orbital implant trends. Br J Ophthalmol. 2006;91:616-619.

18. Tabatabaee Z, Mazloumi M, Rajabi M, Khalilzadeh O, Kassaee A, Moghimi S, et al. Comparison of the exposure rate of wrapped hydroxyapatite (Bio-Eye) versus unwrapped porous polyethylene (Medpor) orbital implants in enucleated patients. Ophthalmic Plast Reconstr Surg. 2011;27:114-118.

19. Lin C, Liao S. Long-term complications of different porous orbital implants: a 21-year review. Br J Ophthalmol. 2016; 101:681-685.

20. Alwitry A, West S, King J, Foss A, Abercrombie L. Long-term follow-up of porous polyethylene spherical implants after enucleation and evisceration. Ophthalmic Plast Reconstr Surg. 2007;23:11-15.

21. Yoon J, Lew H, Kim S, Lee S. Exposure rate of hydroxyapatite orbital implants. Ophthalmology. 2008;115:566-572.e2.

22. Oestreicher J, Liu E, Berkowitz M. Complications of hydroxyapatite orbital implants. Ophthalmology. 1997;104:324-329.

23. Christmas N. Intraorbital implants after enucleation and their complications. Arch Ophthalmol. 1998;116:1199.

24. Inkster C, Ng S, Leatherbarrow B. Primary banked scleral patch graft in the prevention of exposure of hydroxyapatite orbital implants. Ophthalmology. 2002;109:389-392.

25. Jordan D, Gilberg S, Bawazeer A. Coralline hydroxyapatite orbital implant (Bio-Eye): experience with 158 patients. Ophthalmic Plast Reconstr Surg. 2004;20:69-74.

26. Perry J, Goldberg R, McCann J, Shorr N, Engstrom R, Tong J. Bovine hydroxyapatite orbital implant. Ophthalmic Plast Reconstr Surg. 2002;18:268-274.

27. Liang T, Zhao GQ, Meng XX, Zhang LY. Clinical analysis of hydroxyapatite orbital implantation after ocular trauma in 211 cases. Chin J Traumatol. 2006;9:282-7.

28. Gupta M, Lyon F, Singh A, Rundle P, Rennie I. Bovine pericardium (Tutopatch) wrap for hydroxyapatite implants. Eye. 2006;21:476-479.

29. Shields C, Uysal Y, Marr B, Lally S, Rodriques E, Kharod B, et al. Experience with the polymer-coated hydroxyapatite implant after enucleation in 126 patients. Ophthalmology. 2007;114:367-373.

30. Sagoo M. Autogenous temporalis fascia patch graft for porous polyethylene (Medpor) sphere orbital implant exposure. Br J Ophthalmol. 2004;88:942-946.

31. Martin P. Repair of exposed hydroxyapatite orbital implant by a tarsoconjunctival pedicle flap. Ophthalmology. 1998; 105:1694-1697.

32. Shields C, Shields J, Eagle R, De Potter P. Histopathologic evidence of fibrovascular ingrowth four weeks after placement of 
the hydroxyapatite orbital implant. Am J Ophthalmol. 1991; 111:363-366.

33. Sadiq S, Mengher L, Lowry J, Downes R. Integrated orbital implants-a comparison of hydroxyapatite and porous polyethylene implants. Orbit. 2008;27:37-40.
34. Sagoo M. Mechanisms and treatment of extruding intraconal implants. Arch Ophthalmol. 2007;125:1616.

35. Nunery W, Heinz G, Bonnin J, Martin R, Cepela M. Exposure rate of hydroxyapatite spheres in the anophthalmic socket. Ophthalmic Plast Reconstr Surg. 1993;9:96-104. 